\title{
A comparative study of the efficacy of radial and focused shock wave therapy for tennis elbow depending on symptom duration
}

\author{
Magdalena Stania ${ }^{1}$, Barbara Król2 , Andrzej Franek², Edward Błaszczak², Paweł Dolibog², \\ Anna Polak ${ }^{3}$, Patrycja Dolibog ${ }^{2}$, Jacek Durmała ${ }^{4}$, Piotr Król ${ }^{1}$
}

\author{
${ }^{1}$ Institute of Sport Sciences, The Jerzy Kukuczka Academy of Physical Education, \\ Katowice, Poland \\ 2Department of Medical Biophysics, School of Medicine in Katowice, \\ Medical University of Silesia in Katowice, Poland \\ ${ }^{3}$ Institute of Physiotherapy and Health Sciences, The Jerzy Kukuczka Academy \\ of Physical Education, Katowice, Poland \\ ${ }^{4}$ Department of Rehabilitation, School of Health Sciences in Katowice, \\ Medical University of Silesia in Katowice, Poland
}

Submitted: 20 April 2018; Accepted: 20 December 2018

Online publication: 6 April 2020

Arch Med Sci 2021; 17 (6): 1686-1695

DOI: https://doi.org/10.5114/aoms.2019.81361

Copyright $\odot 2020$ Termedia \& Banach

\begin{abstract}
Introduction: In physical therapy, the duration and severity of pain complaints determine the choice of an appropriate physical agent and parameters needed. The aim of this study was to compare the therapeutic efficacy of focused and radial shock waves for tennis elbow with respect to the dysfunction period. Material and methods: The patients with acute $(n=27)$ and chronic $(n=31)$ tennis elbow were randomly assigned to a treatment arm: focused shock wave therapy ( 3 sessions, 2000 shocks, $4 \mathrm{~Hz}, 0.2 \mathrm{~mJ} / \mathrm{mm}^{2}$ ) or radial shock wave therapy (3 sessions, 2000 shocks, $8 \mathrm{~Hz}, 2.5$ bar). In order to objectivize therapy effects, the severity of pain complaints (Visual Analog Scale), strength of wrist flexors and extensors and grip strength were assessed. We performed pre-intervention measurements and short-term follow-up at 1,6 and 12 weeks of therapy completion.

Results: At 6 and 12 weeks of therapy completion, all groups exhibited significantly reduced pain complaints $(p<0.05)$. The most noticeable changes in grip strength, wrist extensors and flexors strength were observed in the affected extremities of all experimental groups while changes within the unaffected extremities were slight. Grip strength as well as the strength of flexor and extensor muscles of the affected limb were significantly greater at 12 weeks of therapy completion compared to pre-intervention values $(p<0.05)$. At the same time point, percent changes of all study parameters were comparable for all groups $(p>0.05)$.

Conclusions: Focused and radial shock wave therapy tend to show a significant and comparable short-term therapeutic effect for acute and chronic tennis elbow.
\end{abstract}

Key words: lateral epicondylitis, extracorporeal shock wave therapy, therapy.

\section{Introduction}

Tendinopathy is among the most common musculoskeletal system disorders. Tennis elbow (lateral epicondylitis) affects 1\% to $3 \%$ of the general population [1].

\author{
Corresponding author: \\ Piotr Król PhD Dsc \\ Institute of Sport Sciences \\ The Jerzy Kukuczka Academy \\ of Physical Education \\ 72a Mikołowska St \\ 40-065 Katowice, Poland \\ Phone: +48 322075129 \\ Fax: +4832 2511097 \\ E-mail: p.krol@awf.katowice.pl
}


Tennis elbow is a non-inflammatory fibroblastic and vascular response to abnormal healing of tendinous tissue damage due to injury or repetitive overuse-related microtrauma. The predominant symptoms, i.e., pain in the outer part of the elbow and local tenderness over the lateral epicondyle of the humerus, may lead to loss of function in the affected limb [2]. The symptoms of tennis elbow can persist for a few weeks to a few months.

A large variety of conservative treatments are initially used including physical therapy (ultrasound, ionophoresis, electric stimulation therapy, eccentric extension exercises, soft tissue mobilization and deep transverse friction massage) [1, 2]. Extracorporeal shock wave therapy (ESWT) recently emerged as a novel and promising treatment modality that might reduce or even eliminate the need for surgery [3-6].

Timely differentiation between acute or chronic tendinopathy is essential for diagnostic and therapeutic considerations [7]. In physical therapy, the duration and severity of pain complaints determine the choice of an appropriate physical agent and parameters thereof. In the case of neuromuscular dysfunction, the effect of shock wave therapy tends to be dose-dependent and causes symptom improvement over time [8].

Khan et al. [9] emphasized that treatment for early diagnosed overuse tendinosis might take no longer than 6 to 10 weeks; however, once the condition has become chronic, the management can continue for 3 to 6 months. Tendon disorders are long-lasting conditions and usually take a long time to heal. Acute lateral epicondylitis is commonly seen in young competitive athletes while its chronic form predominantly occurs in older individuals [10]. A majority of studies on the efficacy of shock wave therapy were carried out in patients with chronic tennis elbow [11-13]; there is little literature on acute presentations [10, 14, 15]. Duration of lateral epicondylitis symptoms was found to be an effective modifier of early response to ESWT [15]. Significant discrepancies were identified between literature reports regarding the effects of shock wave therapy for the management of tennis elbow. Helbig et al. [14] found that the therapy was the most successful in chronic symptoms of over 35 months in duration and the least efficient in symptoms lasting 3 to 12 months. Rompe et al. [13] noted that extracorporeal shock wave therapy significantly relieved pain and improved function in patients suffering from persistent tennis elbow for more than 12 months. Chung et al. [15] observed that a higher proportion of their study participants with lateral epicondylitis symptoms showed a response to ESWT if the treatment had started within 16 weeks of symptom onset. Köksal et al. [10], on the other hand, described comparable efficacy of shock wave therapy in the treatment of acute ( $<3$ months) and chronic ( $>6$ months) lateral epicondylitis.

According to Chung et al. [15], symptom duration should be a candidate for stratification in future ESWT trials. A review of scientific databases did not reveal any reports comparing the effects of focused or radial shock wave therapy on lateral epicondylitis in relation to symptom duration. Hence, the aim of the study was to compare therapeutic efficacy of focused and radial shock waves in acute and chronic stages of tennis elbow. It was hypothesized that shock wave therapy was an efficient treatment modality for tennis elbow and that its effects depended on the duration of pain complaints.

\section{Material and methods}

A pilot experimental, pretest/posttest randomized group design using four experimental groups was prospectively employed to examine the effect of focused and radial shock waves on lateral epicondylitis in relation to symptom duration.

\section{Subjects}

Fifty-eight individuals with tennis elbow (29 men and 29 women) participated voluntarily in the experiment. They were all in good general condition and did not require emergency medical treatment for any other reason. The symptoms were experienced in the left and right upper limb in 7 and 51 patients, respectively. Fifty-four participants suffered pain in the dominant and four in the non-dominant limb.

The diagnosis of tennis elbow had been made by an orthopaedic surgeon after history taking and physical examination including ultrasound. The physical examination included active and passive range of motion, muscle testing and soft tissue examination, and palpation in order to reproduce the patient's symptoms and differentiate between structures causing the symptoms. The inclusion criteria were pain on palpation of the lateral epicondyle of the humerus; pain was also noted when extending the radiocarpal joint and middle finger against resistance. The differential diagnosis included radiculopathy, entrapment of the posterior interosseus nerve, arthrosis of the radiohumeral joint, osteochondritis dissecans, osteonecrosis and plica synovialis. Ultrasound images of lateral epicondylitis revealed focal or extensive hypoechogenic areas around proximal insertions of forearm extensor muscles consistent with fluid collections, ill-defined tendon margins and loss of normal fibrillar architecture. 
Patients with short-lived pain $(<3$ months) were diagnosed with an acute condition while those who suffered pain for at least 6 months were diagnosed with chronic tennis elbow [10]. Those with pain duration of 3 to 6 months (subacute) were excluded from the analysis. Other exclusion criteria were as follows: age below 18 years, local infection, malignancy, bilateral tennis elbow, car- pal tunnel syndrome, medial epicondylitis, elbow arthritis or instability, generalised polyarthritis, ipsilateral shoulder dysfunction, neurological abnormalities, radial nerve entrapment, cardiac arrhythmia or a pacemaker, cancer, diabetes, physical therapy and/or a corticosteroid injection administered within the previous 6 weeks, use of nonsteroidal anti-inflammatory drugs in the period

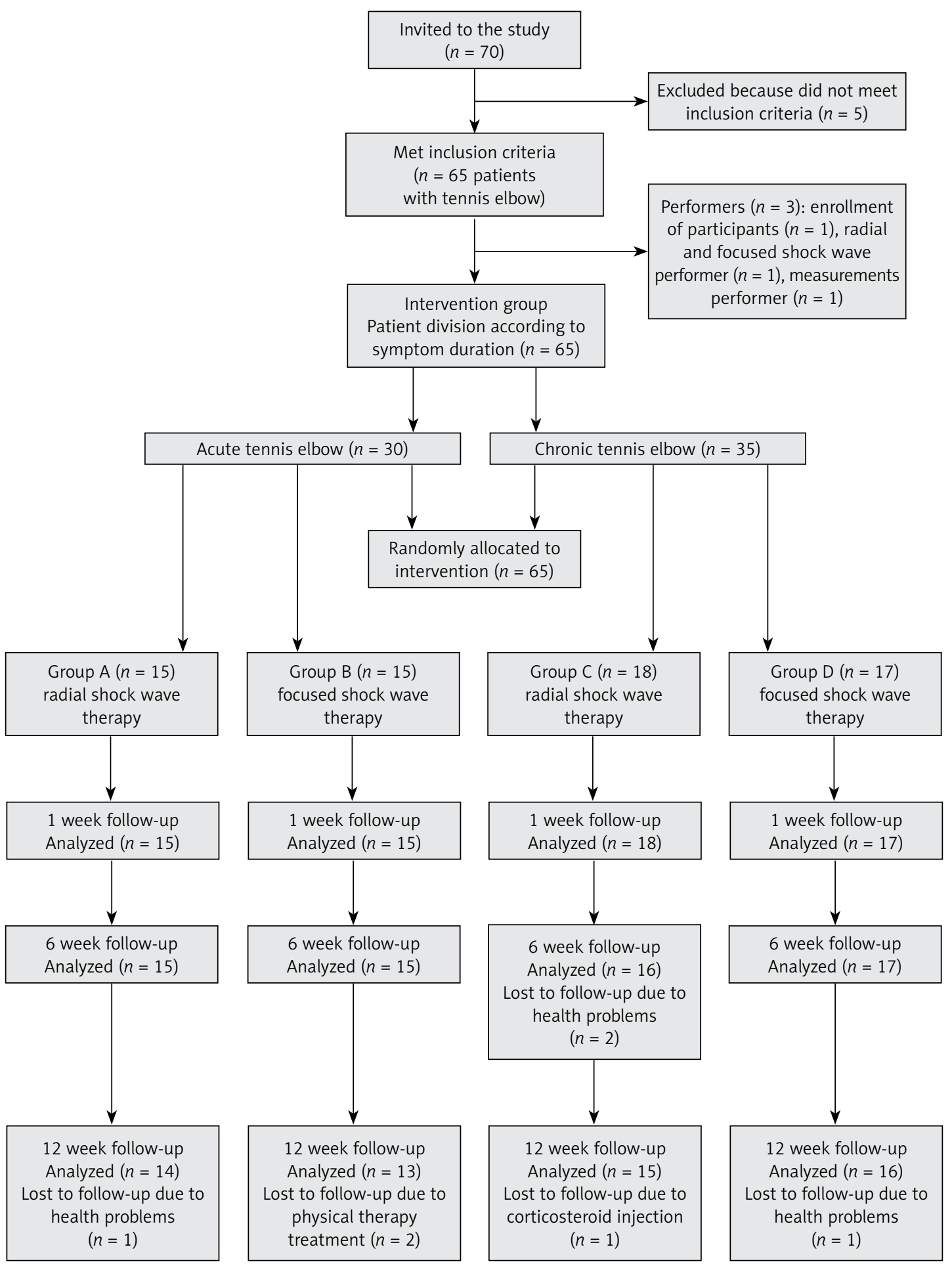

Figure 1. Flow diagram 
Table I. Group characteristics

\begin{tabular}{|c|c|c|c|c|c|}
\hline Group & $n$ & $\begin{array}{l}\text { Age (mean } \pm S D) \\
\quad \text { [years] }\end{array}$ & $\begin{array}{l}\text { Height (mean } \pm \text { SD) } \\
{[\mathrm{cm}]}\end{array}$ & $\begin{array}{l}\text { Body weight (mean } \pm \text { SD) } \\
{[\mathrm{kg}]}\end{array}$ & $\begin{array}{l}\text { Duration of symptoms } \\
\text { (mean } \pm \text { SD) } \\
\text { [months] }\end{array}$ \\
\hline \multicolumn{6}{|c|}{ Acute tennis elbow: } \\
\hline A & 14 & $44.29 \pm 7.89$ & $176.5 \pm 9.09$ & $80.07 \pm 12.46$ & $2.57 \pm 0.51$ \\
\hline B & 13 & $47.23 \pm 8.7$ & $173.54 \pm 7.35$ & $77.53 \pm 16.21$ & $2.69 \pm 0.48$ \\
\hline \multicolumn{6}{|c|}{ Chronic tennis elbow: } \\
\hline$C$ & 15 & $45.73 \pm 7.89$ & $167.47 \pm 7.57$ & $72.4 \pm 17.64$ & $12.2 \pm 6.132$ \\
\hline D & 16 & $49.25 \pm 6.99$ & $169.69 \pm 7.77$ & $76.125 \pm 18.32$ & $12.25 \pm 5.73$ \\
\hline
\end{tabular}

of 6 weeks before study entry and pregnancy. No additional therapies were used within 6 weeks prior to and during the experiment.

The first stage of the investigation consisted of diagnostic tests; the duration of tennis elbow symptoms was also determined. The patients were randomly assigned to a treatment arm. All patients qualified for the study were alternately assigned by a specialist to focused or radial shock wave therapy.

Ultimately, the patients were allocated to one of the four experimental groups:

- Group A: patients with acute tennis elbow treated with radial shock wave,

- Group B: patients with acute tennis elbow treated with focused shock wave,

- Group C: patients with chronic tennis elbow treated with radial shock wave,

- Group D: patients with chronic tennis elbow treated with focused shock wave (Figure 1).

Group characteristics are presented in Table I.

Two patients of Group A, one of Group B, ten of Group $C$ and eight of Group D had received conservative treatment more than 6 weeks prior to recruitment. However, no notable clinical improvement had been observed.

The patients were blinded, i.e., they were informed about the application of shock wave therapy, but not about the therapy type.

All participants gave their written informed consent to participate in this study prior to the experiment. The study was approved by the Ethics Committee of the Institutional Review Board at the Medical University of Silesia in Katowice (resolution number: KNW/0022/KB1/158/10).

\section{Procedures}

All patients receiving focused or radial shock wave therapy were seated with their arm abducted and elbow flexed at approximately $60^{\circ}$; the forearm was pronated and supported, along with the hand, on the treatment table. Prior to the procedure, gel was spread over the target area.
In groups $A$ and $C$, radial shock wave therapy was administered without local anaesthesia using the ShockMaster 500 by Gymna-Uniphy with a standard $15 \mathrm{~mm}$ applicator. In both groups, two thousand pulses per session were applied at a frequency of $8 \mathrm{~Hz}$ and a pressure of 2.5 bars onto the point of maximal tenderness at the lateral epicondyle.

In groups B and D, focused shock wave therapy was administered without local anaesthesia using the Wolf PiezoWave unit featuring a piezo-electric shock wave source with a bowl-shaped gel applicator. Shock wave energy was focused $0.5 \mathrm{~cm}$ over the applicator's tip. Two thousand shocks were applied at a frequency of $4 \mathrm{~Hz}$ and energy flux density of $0.2 \mathrm{~mJ} / \mathrm{mm}^{2}$.

Each study participant received 3 treatment sessions held at weekly intervals. No shock wave was applied to the unaffected limb.

Chen et al. [16] assessed therapy impact based on clinical and functional outcomes. In our experiment we assessed the severity of pain complaints, strength of wrist flexors and extensors and grip strength of the affected and unaffected extremities. All measurements were performed prior to shock wave interventions and at 1, 6 and 12 weeks of therapy completion.

Similar to other studies [17], pain intensity was assessed with the Visual Analog Scale (VAS) with 0 representing "no pain" and 10 the "worst possible pain".

Grip strength and the strength of wrist flexors and extensors were measured with the Saehan Hydraulic Hand Dynamometer, model SH5001.

Grip strength $(\mathrm{kG})$ was measured in the sitting position with the patient's arm abducted and elbow flexed at $90^{\circ}$; the forearm was in the mid-position between supination and pronation. Each patient was allowed three attempts to squeeze the dynamometer with maximum strength with $30 \mathrm{~s}$ breaks in between. The mean of the three attempts was used for statistical analysis.

Wrist extensors strength $(\mathrm{kG})$ was measured in the seated position. The patient's arm was adduct- 
ed and the elbow flexed at $90^{\circ}$. The forearm was placed in supination and supported on the treatment table; the wrist was flexed and fingers extended. The moving arm of the dynamometer was each time set in the lowest position. The participants pressed the dynamometer with the distal dorsal segment of the metacarpus.

Wrist flexors strength $(\mathrm{kG})$ was measured in the seated position. The patient's arm was adducted and elbow flexed at $90^{\circ}$. The forearm was placed in pronation and supported on the treatment table; the wrist and fingers were extended. The moving arm of the dynamometer was set in the lowest position. The participants pressed the dynamometer with the distal palmar segment of the metacarpus.

Each patient performed three consecutive attempts at maximal wrist extension and flexion with 30 s breaks in between. The mean of the three attempts was used for statistical analysis.

Treatment outcomes for patients with tennis elbow were as follows:

- mean strength of wrist extensors and flexors in the affected and unaffected extremity,

- a ratio value of mean wrist extensors strength in affected to unaffected extremity,

- a ratio value of mean wrist flexors strength in affected to unaffected extremity,

- mean grip strength of the affected and unaffected extremity,

- a ratio value of mean grip strength in the affected to unaffected extremity.

Percentage change in muscle strength was derived from the following formula:

$$
X(\%)=\frac{\left(X_{k}-X_{p}\right)}{X_{p}} \times 100(\%)
$$

where: $X=$ percentage change, $X_{p}=$ average strength before treatment, $X_{k}=$ average strength 12 weeks after treatment.
To calculate percentage change in the amount of pain felt by patients the following formula was used:

$$
Y(\%)=\frac{\left(Y_{p}-Y_{k}\right)}{Y_{p}} \times 100(\%)
$$

where: $Y=$ percentage change in the amount of pain, $Y_{p}=$ average amount of pain before treatment, $Y_{k}^{p}=$ average amount of pain 12 weeks after treatment.

\section{Statistical analysis}

To investigate the homogeneity of distribution of patients' characteristics and of all selected parameters, the Kruskal-Wallis ANOVA by ranks and the post-hoc test were used.

Changes inside groups were examined using Friedman's ANOVA test and the post-hoc test. Changes between groups were compared using the Kruskal-Wallis test by ranks. The level of significance in all tests was $p \leq 0.05$.

\section{Results}

The study population was homogeneous with respect to individual participant characteristics $(p<0.05)$.

At 6 and 12 weeks of therapy completion, all groups exhibited significantly reduced pain complaints $(p<0.05)$. The severity of pain at 1 week of therapy completion did not differ significantly compared to pre-intervention scores $(p>0.05)$ (Figure 2).

The most noticeable changes in grip strength were observed in the affected extremities. All groups exhibited a significant increase in grip strength of the affected extremity at weeks 6 and 12 of therapy completion $(p<0.05)$ while only slight changes were observed in grip strength

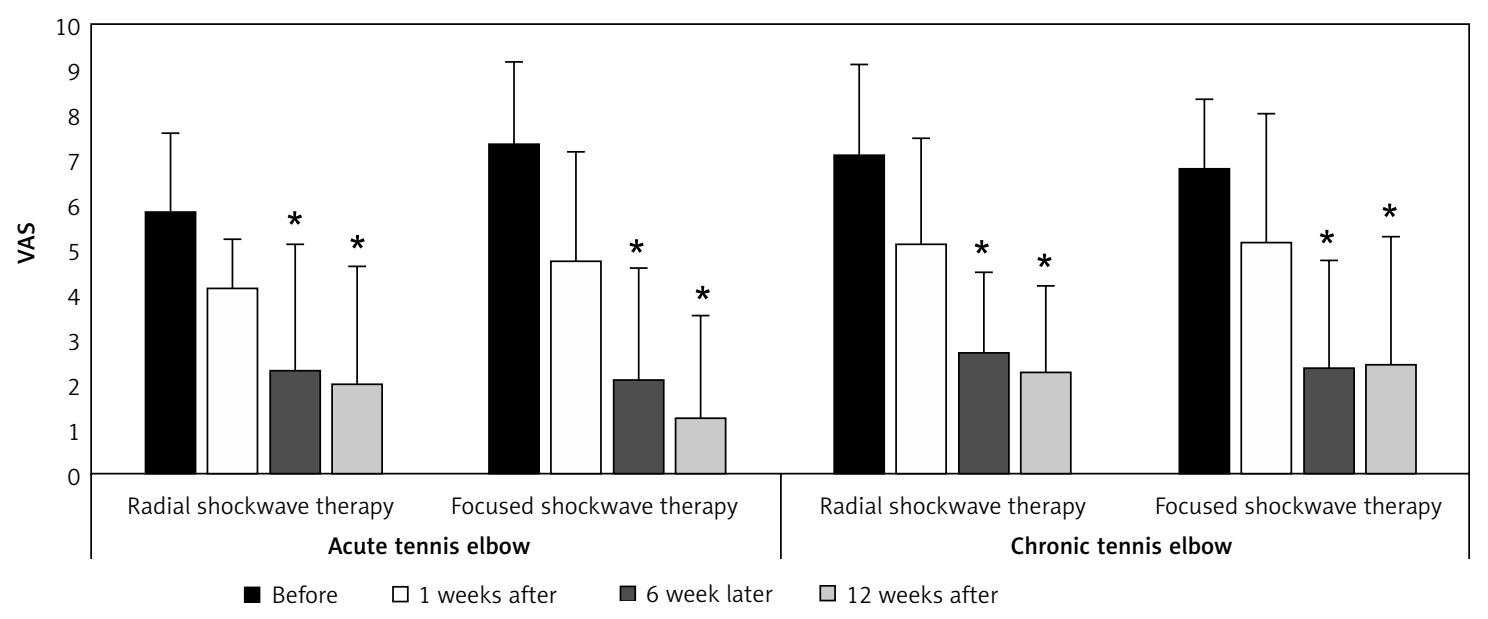

Post-hoc test for Friedman ANOVA by ranks, against the baseline. ${ }^{*} p \leq 0.05$.

Figure 2. Changes in the mean activity-related pain intensity scores $( \pm S D)-$ all experimental groups during the whole observation period 
Table II. Change of the grip strength of the affected and unaffected extremity in all groups (mean \pm SD)

\begin{tabular}{|c|c|c|c|c|}
\hline Grip strength & Baseline & 1 week & 6 weeks & 12 weeks \\
\hline \multicolumn{5}{|l|}{ Group A: } \\
\hline Affected extremity & $37 \pm 7.07$ & $42 \pm 10.98$ & $43.21 \pm 11.09^{*}$ & $44.71 \pm 12.28^{*}$ \\
\hline Unaffected extremity & $43.93 \pm 12.44$ & $44.43 \pm 12.65$ & $44.86 \pm 13.2$ & $44.86 \pm 13.1$ \\
\hline Ratio & $0.87 \pm 0.19$ & $0.97 \pm 0.17$ & $0.99 \pm 0.17$ & $1.02 \pm 0.16^{\star}$ \\
\hline \multicolumn{5}{|l|}{ Group B: } \\
\hline Affected extremity & $34.46 \pm 8.17$ & $37.46 \pm 9.21$ & $41.31 \pm 9.07^{*}$ & $41.92 \pm 8.82^{*}$ \\
\hline Unaffected extremity & $40.54 \pm 9.26$ & $41.23 \pm 9.76$ & $41.85 \pm 9.8$ & $41.92 \pm 9.37$ \\
\hline Ratio & $0.86 \pm 0.15$ & $0.92 \pm 0.15$ & $0.99 \pm 0.09$ & $1.01 \pm 0.1^{\star}$ \\
\hline \multicolumn{5}{|l|}{ Group C: } \\
\hline Affected extremity & $35.6 \pm 12.16$ & $38 \pm 13.45$ & $41.13 \pm 12.32^{*}$ & $41.67 \pm 11.84^{\star}$ \\
\hline Unaffected extremity & $38.93 \pm 10.45$ & $39.87 \pm 12.09$ & $41.07 \pm 12.8^{\star}$ & $40.93 \pm 12.76$ \\
\hline Ratio & $0.93 \pm 0.32$ & $0.97 \pm 0.31$ & $1.03 \pm 0.27^{\star}$ & $1.05 \pm 0.27^{*}$ \\
\hline \multicolumn{5}{|l|}{ Group D: } \\
\hline Affected extremity & $37.31 \pm 11.94$ & $41.63 \pm 11.76$ & $44.94 \pm 11.91^{*}$ & $44.63 \pm 12.04^{*}$ \\
\hline Unaffected extremity & $41.75 \pm 9.46$ & $42.19 \pm 9.45$ & $42.56 \pm 9.14$ & $42.94 \pm 9.68$ \\
\hline Ratio & $0.91 \pm 0.26$ & $0.99 \pm 0.2$ & $1.06 \pm 0.18$ & $1.04 \pm 0.18$ \\
\hline
\end{tabular}

The post-hoc test for Friedman ANOVA by ranks, against the baseline. ${ }^{*} p \leq 0.05$.

Table III. Change of the strength of wrist extensors of the affected and unaffected extremity in all groups (mean \pm SD)

\begin{tabular}{|c|c|c|c|c|}
\hline Strength of wrist extensors & Baseline & 1 week & 6 weeks & 12 weeks \\
\hline \multicolumn{5}{|l|}{ Group A: } \\
\hline Affected extremity & $9.57 \pm 3.13$ & $12.79 \pm 3.91^{\star}$ & $14.21 \pm 5.04^{\star}$ & $14.79 \pm 5.41^{*}$ \\
\hline Unaffected extremity & $12.79 \pm 4.06$ & $13.71 \pm 4.05$ & $13.86 \pm 4.15$ & $13.86 \pm 4.13$ \\
\hline Ratio & $0.77 \pm 0.23$ & $0.95 \pm 0.19$ & $1.04 \pm 0.20^{*}$ & $1.07 \pm 0.20^{\star}$ \\
\hline \multicolumn{5}{|l|}{ Group B: } \\
\hline Affected extremity & $8.23 \pm 2.45$ & $10.15 \pm 4.18$ & $10.85 \pm 4.14$ & $11.08 \pm 4.19^{*}$ \\
\hline Unaffected extremity & $11.77 \pm 4.36$ & $12.69 \pm 4.44$ & $11.77 \pm 4.30$ & $12.08 \pm 4.13$ \\
\hline Ratio & $0.76 \pm 0.26$ & $0.83 \pm 0.29$ & $0.96 \pm 0.26^{*}$ & $0.94 \pm 0.23^{*}$ \\
\hline \multicolumn{5}{|l|}{ Group C: } \\
\hline Affected extremity & $10.60 \pm 4.95$ & $11.93 \pm 4.92^{*}$ & $13.40 \pm 4.50^{*}$ & $13.67 \pm 4.37^{*}$ \\
\hline Unaffected extremity & $11.47 \pm 4.97$ & $12.13 \pm 4.98$ & $13.13 \pm 4.73^{*}$ & $13.47 \pm 4.56^{*}$ \\
\hline Ratio & $0.92 \pm 0.38$ & $1.00 \pm 0.28$ & $1.03 \pm 0.16$ & $1.03 \pm 0.13$ \\
\hline \multicolumn{5}{|l|}{ Group D: } \\
\hline Affected extremity & $9.94 \pm 3.85$ & $11.38 \pm 3.10$ & $12.31 \pm 3.32$ & $12.38 \pm 3.36^{*}$ \\
\hline Unaffected extremity & $12.25 \pm 3.96$ & $13.06 \pm 3.99$ & $12.06 \pm 3.34$ & $12.37 \pm 3.57$ \\
\hline Ratio & $0.84 \pm 0.26$ & $0.90 \pm 0.18$ & $1.03 \pm 0.10^{*}$ & $1.01 \pm 0.09$ \\
\hline
\end{tabular}

The post-hoc test for Friedman ANOVA by ranks, against the baseline. ${ }^{*} p \leq 0.05$.

of the healthy limb. However, the ratio of mean ity increased significantly in groups $A, B$ and $C$ at grip strength in the affected to unaffected extrem- 12 weeks of therapy completion $(p<0.05)$ (Table II). 
Magdalena Stania, Barbara Król, Andrzej Franek, Edward Błaszczak, Paweł Dolibog, Anna Polak, Patrycja Dolibog, Jacek Durmała, Piotr Król

Table IV. Change of the strength of wrist flexors of the affected and unaffected extremity in all groups (mean \pm SD)

\begin{tabular}{|lllll|}
\hline Strength of wrist flexors & Baseline & 1 week & 6 weeks & 12 weeks \\
\hline \begin{tabular}{l} 
Group A: \\
\hline Affected extremity
\end{tabular} & $15.00 \pm 4.69$ & $17.57 \pm 4.96^{*}$ & $17.71 \pm 5.65^{*}$ & $17.36 \pm 5.53^{*}$ \\
\hline Unaffected extremity & $16.21 \pm 4.99$ & $16.86 \pm 5.56$ & $16.71 \pm 5.44$ & $16.86 \pm 5.56$ \\
\hline Ratio & $0.93 \pm 0.12^{*}$ & $1.07 \pm 0.15^{*}$ & $1.08 \pm 0.17^{*}$ & $1.05 \pm 0.17^{*}$ \\
\hline $\begin{array}{l}\text { Group B: } \\
\text { Affected extremity }\end{array}$ & $13.38 \pm 3.48$ & $16.54 \pm 7.02$ & $17.85 \pm 8.46$ & $18.31 \pm 8.23^{*}$ \\
\hline Unaffected extremity & $16.15 \pm 6.58$ & $16.62 \pm 6.60$ & $17.39 \pm 7.02$ & $16.62 \pm 6.60$ \\
\hline Ratio & $0.91 \pm 0.31$ & $1.04 \pm 0.36$ & $1.06 \pm 0.33$ & $1.13 \pm 0.30$ \\
\hline Group C: & & & \\
\hline Affected extremity & $15.47 \pm 4.73$ & $16.27 \pm 3.69^{*}$ & $17.47 \pm 4.22^{*}$ & $17.53 \pm 4.49^{*}$ \\
\hline Unaffected extremity & $16.87 \pm 5.14$ & $16.60 \pm 4.67$ & $16.93 \pm 5.06^{*}$ & $16.93 \pm 5.19$ \\
\hline Ratio & $0.93 \pm 0.16$ & $1.00 \pm 0.14$ & $1.05 \pm 0.15^{*}$ & $1.06 \pm 0.14^{*}$ \\
\hline Group D: & & & & \\
\hline Affected extremity & $14.75 \pm 3.75$ & $16.75 \pm 3.84$ & $18.31 \pm 5.26^{*}$ & $18.69 \pm 5.59^{*}$ \\
\hline Unaffected extremity & $17.56 \pm 6.93$ & $18.50 \pm 6.66$ & $18.50 \pm 6.14$ & $18.69 \pm 6.07$ \\
\hline Ratio & $0.97 \pm 0.47$ & $0.98 \pm 0.32$ & $1.03 \pm 0.27$ & $1.04 \pm 0.26$ \\
\hline
\end{tabular}

The post-hoc test for Friedman ANOVA by ranks, against the baseline. ${ }^{*} p \leq 0.05$.

Table V. Percentage change in the analysed parameters in all comparative groups

\begin{tabular}{|c|c|c|c|c|c|}
\hline Group & $A(\% \pm S D)$ & $\mathrm{B}(\% \pm \mathrm{SD})$ & $C(\% \pm S D)$ & $\mathrm{D}(\% \pm \mathrm{SD})$ & $P$-value \\
\hline Pain during activity & $66.68 \pm 38.71$ & $84.61 \pm 25.19$ & $67.00 \pm 32.53$ & $65.73 \pm 40.90$ & $>0.05$ \\
\hline Grip strength of the affected extremity & $21.94 \pm 25.77$ & $23.92 \pm 20.92$ & $21.01 \pm 21.17$ & $23.61 \pm 26.73$ & $>0.05$ \\
\hline Grip strength of the unaffected extremity & $2.00 \pm 6.40$ & $3.60 \pm 6.87$ & $4.26 \pm 8.63$ & $2.92 \pm 5.31$ & $>0.05$ \\
\hline $\begin{array}{l}\text { Wrist extensor strength of the affected } \\
\text { extremity }\end{array}$ & $65.92 \pm 67.84$ & $35.52 \pm 33.18$ & $40.53 \pm 33.95$ & $36.96 \pm 55.74$ & $>0.05$ \\
\hline $\begin{array}{l}\text { Wrist extensor strength of the unaffected } \\
\text { extremity }\end{array}$ & $10.66 \pm 20.90$ & $4.65 \pm 18.29$ & $28.62 \pm 56.84$ & $3.72 \pm 17.54$ & $>0.05$ \\
\hline Wrist flexor strength of the affected extremity & $17.12 \pm 17.73$ & $35.11 \pm 36.20$ & $16.40 \pm 20.33$ & $29.11 \pm 33.65$ & $>0.05$ \\
\hline $\begin{array}{l}\text { Wrist flexor strength of the unaffected } \\
\text { extremity }\end{array}$ & $4.34 \pm 17.67$ & $4.12 \pm 12.78$ & $1.74 \pm 16.54$ & $11.73 \pm 20.01$ & $>0.05$ \\
\hline Extensor strength ratio (affected to unaffected) & $46.82 \pm 38.62$ & $32.30 \pm 38.94$ & $18.63 \pm 39.04$ & $34.36 \pm 56.22$ & $>0.05$ \\
\hline Flexor strength ratio (affected to unaffected) & $13.13 \pm 13.33$ & $31.52 \pm 38.86$ & $16.13 \pm 23.25$ & $19.52 \pm 40.66$ & $>0.05$ \\
\hline Grip strength ratio (affected to unaffected) & $19.21 \pm 21.54$ & $20.41 \pm 23.29$ & $17.39 \pm 27.29$ & $20.33 \pm 27.18$ & $>0.05$ \\
\hline
\end{tabular}

Changes in wrist extensors (Table III) and flexors strength (Table IV) were comparable to changes in grip strength. The greatest strength increase was noted in the affected extremities, while the changes in the unaffected extremities were small. All study groups exhibited significantly greater strength of wrist extensors and flexors of the affected limb at 12 weeks of therapy com- pletion compared to pre-intervention measurements $(p<0.05)$. The above changes were associated with an increase in the ratio of affected extremity extensors/flexors strength to unaffected extremity extensors/flexors strength.

At 12 weeks of therapy completion, percent changes of all study parameters were comparable for all groups $(p>0.05)$ (Table V). 


\section{Discussion}

In our experiment both focused and radial shock wave therapy protocols proved efficient for acute and chronic pain complaints as well as restoration of muscle strength in the affected extremity. It was demonstrated that both treatment protocols showed comparable short-term therapeutic effects. To our knowledge, this is the first study to compare therapeutic efficacy of focused and radial shock waves for tennis elbow with respect to the dysfunction period.

The probability of full recovery from chronic symptoms associated with tendinopathy has been estimated at $80 \%$ [9]. Hammer et al. [4] reported a $63 \%$ success rate of ESWT at 6 months of treatment completion, while the proportion of satisfied patients in the group of Spacca et al.'s study [5] was as high as $84 \%$. Follow-up examination performed by Wang and Chen [18] at 12 to 24 months after shock wave therapy confirmed complete resolution of tennis elbow symptoms in $61.4 \%$ of their patients while $29.5 \%$ were significantly better. Nevertheless, there are also studies whose results showed no evidence that extracorporeal shock wave therapy for tennis elbow outperformed the outcomes of placebo [11, 12] or other therapeutic interventions including acupuncture [19] or percutaneous tenotomy [3].

Our statistical analysis revealed satisfactory and comparable efficacy of both focused and radial shock wave therapy for acute and chronic tennis elbow.

The beneficial effect of ESWT in patients with chronic symptoms might be associated with reparative tissue abnormalities which make it more susceptible to disruption by shock waves [14]. As concerns acute tennis elbow, Ciccotti et al. [20] emphasize that although patients describe pain as acute, the degenerative character of the dysfunction indicates that the tendon's adaptation to tensile overloading has been impaired long before symptom occurrence. It is therefore likely that, in the acute phase of tennis elbow, the mechanism of shock wave action on soft tissues consists of a disruptive effect - similar to that observed in reparative tissues. It has been speculated that shock waves might reactivate the healing process through microdisruption of avascular or minimally vascularized tissues [21], resulting in neovascularization, improved blood supply and stimulation of tissue regeneration [22]. Animal experiments showed that shock wave therapy induced early release of angiogenesis-mediating growth factors and hence neovascularization. The resultant improvement of blood supply and cell proliferation caused tissue regeneration and tendon repair [8].

Similar to our experiment, Köksal et al. [10] also observed a beneficial effect of shock wave therapy in patients with acute and chronic lateral epicondylitis. Other experiments revealed that the therapeutic efficacy of ESWT correlated with the duration of pain complaints. Helbig et al. [14] concluded that patients with chronic (> 35 months) symptoms of lateral epicondylitis were more likely to exhibit positive results of shock wave therapy, while Chung et al. [15] reported that a higher proportion of positive response to ESWT was shown by subjects treated within 16 weeks of symptom onset. It should be noted though that the above discrepancies between findings might have been caused by methodological differences. Köksal et al. [10] applied radial shock waves in a total of 3 treatment sessions held at 3-day intervals. Each patient received 2000 shocks per session with 2.5 bars and frequency of $5 \mathrm{~Hz}$. Helbig et al. [14] used one to three focused ESWT sessions administered at 4-week intervals. Each session comprised 800 impulses; energy flux density was $0.08 \mathrm{~mJ} / \mathrm{mm}^{2}$. Chung et al.'s [15] patients received 3 focused shock wave treatments of 2000 pulses each (once a week); energy flux density was 0.03 to $0.17 \mathrm{~mJ} / \mathrm{mm}^{2}$.

All participants of our experiment exhibited gradual improvement in physical activity-associated pain following therapy completion. In all experimental groups pain reduction was statistically significant at 6 and 12 weeks of therapy completion. The intergroup differences in post-therapy VAS scores did not differ significantly. A gradual decrease in pain symptoms after shock wave therapy was also observed by other researchers $[11,13]$. Shock wave-related pain relief has also been attributed to a decrease in substance $P$ release from the treated area [23], selected loss of unmyelinated nerve fibres at the sites of shock wave applications [24], and activation of the serotonergic system [13] or pain suppression system at the level of the spinal cord [25].

At all time points after shock wave therapy all groups exhibited an increase in the affected extremity grip strength compared to pre-intervention measurements. The most noticeable changes were seen at 6 and 12 weeks of therapy completion. Only slight changes were noted in grip strength of the unaffected extremities with a resultant increase in the ratio value of mean grip strength in the affected to unaffected extremity. In the experiment of Gündüz et al. [26], grip strength increase in tennis elbow sufferers was found at the first, third and sixth months of radial shock wave therapy (10 sessions of 500 shocks each; pressure 1.4 bar). The increase was associated with pain reduction. On the other hand, after 3, 6 and 24 weeks of focused shock wave treatment $\left(0.08 \mathrm{~mJ} / \mathrm{mm}^{2}, 3\right.$ sessions of 1000 impulses each), Rompe et al. [13] ob- 
served a decreased grip strength despite significant pain relief.

All groups also demonstrated an increase in the mean strength of wrist extensors and flexors in the affected extremity compared to pre-intervention measurements. The greatest increase was noted at 6 and 12 weeks of therapy completion (except for wrist flexors strength in Group A). Simultaneous but apparently negligible changes in the strength of both muscle groups in the unaffected extremities caused ratio values of the mean wrist extensors and flexors strength in the affected to unaffected extremity to increase.

The above-mentioned post-intervention gain in both muscle groups' strength and grip strength probably resulted from pain reduction and hence greater involvement of the affected extremity in physical activity.

Our analysis indicates that focused and radial shock wave therapies do not induce a rapid improvement of the patient's symptoms; rather, they initiate reparative processes within injured tissues. Our patients exhibited gradual reduction of pain complaints associated with the gradual increase in muscle strength in the affected extremity. The first post-treatment measurement did not reveal significant pain reduction during physical activity in any of the experimental groups. Therapy benefits, i.e., an increase in muscle groups' and grip strength of the affected extremity, were mainly seen at 6 and/or 12 weeks of therapy completion.

Shock waves enhance the release of angiogenesis markers, which remains high for 8 weeks. The neovascularization process starts after 4 weeks and persists for 12 weeks or even longer [8]. Optimization of collagen synthesis, maturation and strength progressively increases the tendon's tensile strength and hence also recovery [9]. Collagen neosynthesis within the affected tendon [9] and neovascularization [8] seem to account for the gradual and long-term benefits of shock wave therapy in tennis elbow. Long-lasting benefits of shock wave therapy (up to 24 weeks) were observed by Atthakomol et al. [27].

In a short-term follow-up, radial and focused shock wave therapies were equally effective for acute and chronic stages of tennis elbow. From a medical point of view it does not seem significant whether focused/radial shock waves are used in a disease of short or long duration as beneficial results can be obtained in all cases. Our results indicate that either of these two can be used depending on convenience and availability. It may be that long-term results will provide arguments in favour of either focused or radial shock waves but, at the moment, nothing seems to indicate this. The use of focused/radial shock waves does not exclude application of other physical agents or pharmacotherapy, especially because no adverse effects of shock wave therapy have been noted.

A number of treatments have been used for tennis elbow. So far, the effects of shock wave therapy have been compared to those of corticosteroid injections [28, 29], autologous blood injections [28], other physical therapies [26] and acupuncture [30]. Corticosteroid injections yielded significantly better results but only at 4 weeks [28]. Other authors did not reveal therapeutic superiority of any of the following interventions: combined physical therapy (hot packs, ultrasound, transverse massage), corticosteroid injection combined with local anaesthetic and extracorporeal shock wave treatment [26]. Ozturan et al. [28] concluded that long-term results of autologous blood injection and extracorporeal shock wave therapy were comparable. Unfortunately, due to considerable discrepancies between shock wave applications and methods of therapy effects assessment, it remains difficult to draw unambiguous conclusions regarding the efficacy of extracorporeal shock wave for tennis elbow.

Adverse effects of extracorporeal shock wave therapy may include transient skin reddening, small areas of subcutaneous extravasation resulting from small vessel injury, bruises, local swelling and numbness of the area. The most frequent intra-intervention complaint is pain in the shock wave application area [31, 32], which was in fact the only adverse effect observed in our study and reported by 7 patients in Group A, 6 patients in Group B, 4 patients in Group C and 4 patients in Group D. Nevertheless, all these patients perceived the pain level as tolerable and did not report any pain at the completion of shock wave sessions. Two patients in Group A, 3 patients in Group B, 1 patient in Group $C$ and 2 patients in Group D had petechiae and minor oedema near the lateral epicondyle during shock wave application, which resolved before the next treatment session.

Experimental research is known to have some specific limitations. The major limitation to our study is the lack of long-term follow-up. Furthermore, diagnostic imaging of lateral epicondylitis was limited to ultrasound examination. We did not use imaging modalities that allow very accurate assessment of pathologies within the affected tendon such as magnetic resonance imaging.

In conclusion, focused and radial shock waves administered in patients with tennis elbow seem to yield a significant and comparable therapeutic effect which does not depend on the duration of pain symptoms characteristic of this condition. The following therapy parameters have provided beneficial effects, i.e., increase in wrist flexors and extensors strength and grip strength as well as 
pain reduction: 1) focused shock wave therapy: 3 sessions, 2000 shocks, $4 \mathrm{~Hz}, 0.2 \mathrm{~mJ} / \mathrm{mm}^{2}$, 2) radial shock wave therapy: 3 sessions, 2000 shocks, $8 \mathrm{~Hz}, 2.5$ bar.

\section{Conflict of interest}

The authors declare no conflict of interest.

\section{References}

1. Kaux JF, Forthomme B, Le Goff C, Crielaard JM, Croisier JL Current opinions on tendinopathy. J Sports Sci Med 2011; 10: 238-53.

2. De Smedt T, de Jong A, Van Leemput W, Lieven D, Van Glabbeek F. Lateral epicondylitis in tennis: update on aetiology, biomechanics and treatment. Br J Sports Med 2007; 41: 816-9.

3. Radwan Y, El Sobhi G, Badawy WS, Reda A, Khalid S. Resistant tennis elbow: shock-wave therapy versus percutaneous tenotomy. Int Orthop 2008; 32: 671-7.

4. Hammer DS, Rupp S, Ensslin S, Kohn D, Seil R. Extracorporal shock wave therapy in patients with tennis elbow and painful heel. Arch Orthop Trauma Surg 2000; 120: 304-7.

5. Spacca G, Necozione S, Cacchio A. Radial shock wave therapy for lateral epicondylitis: a prospective randomised controlled single-blind study. Eur Med Phys 2005; 41: 17-25.

6. Król P, Franek A, Durmała J, et al. Focused and radial shock wave therapy in the treatment of tennis elbow: a pilot randomised controlled study. J Hum Kinet 2015; 14: 127-35.

7. Gabel GT. Acute and chronic tendinopathies at the elbow. Curr Opin Rheumatol 1999; 11: 138-43.

8. Wang CJ. An overview of shock wave therapy in musculoskeletal disorders. Chang Gung Med J 2003; 26: 220-32.

9. Khan KM, Cook JL, Taunton JE, Bonar F. Overuse tendinosis, not tendinitis part 1: a new paradigm for a difficult clinical problem. Phys Sportsmed 2000; 28: 38-48.

10. Köksal i, Güler O, Mahiroğulları M, Mutlu S, Çakmak S, Akşahin E. Comparison of extracorporeal shock wave therapy in acute and chronic lateral epicondylitis. Acta Orthop Traumatol Turc 2015; 49: 465-70.

11. Melikyan EY, Shahin E, Miles J, Bainbridge LC. Extracorporeal shock-wave treatment for tennis elbow. A randomised double-blind study. J Bone Joint Surg Br 2003; 85: 852-5.

12. Speed CA, Nichols D, Richards C, et al. Extracorporeal shock wave therapy for lateral epicondylitis - a double blind randomised controlled study. J Orthop Res 2002; 20: 895-98.

13. Rompe JD, Hopf C, Kullmer K, et al. Low-energy extracorporal shock wave therapy for persistent tennis elbow. Int Orthop 1996; 20: 23-7.

14. Helbig K, Herbert C, Schostok T, Brown M, Thiele R. Correlations between the duration of pain and the success of shock wave therapy. Clin Orthop Relat Res 2001; 387: 68-71.

15. Chung B, Wiley JP, Rose MS. Long-term effectiveness of extracorporeal shockwave therapy in the treatment of previously untreated lateral epicondylitis. Clin J Sport Med 2005; 15: 305-12.

16. Chen A, Chen X, Shen Y, Li W. Modalities of ventricular pacing for cardiac resynchronization therapy in patients with heart failure: a meta-analysis and systematic review. Arch Med Sci 2017; 13: 1006-17.
17. Kozak-Szkopek E, Broczek K, Slusarczyk P, et al. Prevalence of chronic pain in the elderly Polish population results of the PolSenior study. Arch Med Sci 2017; 13: 1197-206.

18. Wang CJ, Chen HS. Shock wave therapy for patients with lateral epicondylitis of the elbow: a one- to two-year follow-up study. Am J Sports Med 2002; 30: 422-5.

19. Wing-Yee Wong C, Yin-Ling Ng E, Fung PW, Mok KM, Shu-Hang Yung P, Chan KM. Comparison of treatment effects on lateral epicondylitis between acupuncture and extracorporeal shockwave therapy. AP-SMART 2017; 7: 21-6.

20. Ciccotti MC, Schwartz MA, Ciccotti MG. Diagnosis and treatment of medial epicondylitis of the elbow. Clin Sports Med 2004; 23: 693-705.

21. Thiel M. Application of shock waves in medicine. Clin Orthop Relat Res 2001; 387: 18-21.

22. Wang CJ. Extracorporeal shockwave therapy in musculoskeletal disorders. J Orthop Surg Res 2012; 7: 11.

23. Maier M, Milz S, Wirtz DC, Rompe JD, Schmitz C. Basic research of applying extracorporeal shockwaves on the musculoskeletal system. An assessment of current status. Der Orthopade 2002; 31: 667-677.

24. Hausdorf J, Lemmens MA, Heck KD, et al. Selective loss of unmyelinated nerve fibers after extracorporeal shockwave application to the musculoskeletal system. Neuroscience 2008; 155: 138-44.

25. Wess OJ. A neural model for chronic pain and pain relief by extracorporeal shock wave treatment. Urol Res 2008; 36: 327-34.

26. Gündüz R, Malas FÜ, Borman P, Kocaoğlu S, Özçakar L. Physical therapy, corticosteroid injection, and extracorporeal shock wave treatment in lateral epicondylitis. Clinical and ultrasonographical comparison. Clin Rheumatol 2012; 31: 807-12.

27. Atthakomol P, Manosroi W, Phanphaisarn A, Phrompaet S, lammatavee S, Tongprasert S. Comparison of single-dose radial extracorporeal shock wave and local corticosteroid injection for treatment of carpal tunnel syndrome including mid-term efficacy: a prospective randomized controlled trial. BMC Musculoskelet Disord 2018; 25: 32.

28. Ozturan KE, Yucel I, Cakici H, Guven M, Sungur I. Autologous blood and corticosteroid injection and extracoporeal shock wave therapy in the treatment of lateral epicondylitis. Orthopedics 2010; 33: 84-91.

29. Crowther MA, Bannister GC, Huma H, Rooker GD. A prospective, randomised study to compare extracorporeal shock-wave therapy and injection of steroid for the treatment of tennis elbow. J Bone Joint Surg Br 2002; 84: 678-9.

30. Wong CW, Ng EY, Fung PW, Mok KM, Yung PS, Chan KM. Comparison of treatment effects on lateral epicondylitis between acupuncture and extracorporeal shockwave therapy. Asia Pac J Sports Med Arthrosc Rehabil Technol 2016; 24: 21-6.

31. Liu HM, Chao CM, Hsieh JY, Jiang CC. Humeral head osteonecrosis after extracorporeal shock-wave treatment for rotator cuff tendinopathy. A case report. J Bone Joint Surg Am 2006; 88: 1353-6.

32. Husain J, Lynn NN, Jones DK, Collins GN, O'Reilly PH. Extracorporeal shock wave therapy in the management of Peyronie's disease: initial experience. BJU Int 2000; 86: 466-8. 